\title{
Estudio inmunocitoquímico de Receptores de Estrógeno Fracción Alfa y de Progesterona en Pólipos Endometriales
}

\author{
Immunocytochemistry Study of Estrogen Receiver Alfa Fraction \\ and Progesterone in Endometrial Polyps
}

Vasconcellos, A.; Villagrán, E.; Astudillo, M. \& Cabezas, P.

VASCONCELLOS, A.; VILLAGRÁN, E.; ASTUDILLO, M. \& CABEZAS, P. Estudio inmunocitoquímico de receptores de estrógeno fracción alfa y de progesterona en pólipos endometriales. Int. J. Morphol., 23(2):123-127, 2005.

RESUMEN: Los pólipos endometriales son causa frecuente de metrorragia y, en algunos casos, pueden ser responsables de esterilidad. Su patogenia es poco conocida, dando origen a masas sésiles o pedunculadas que protruyen en la cavidad uterina y que histológicamente corresponden a endometrio proliferativo de estroma fibroso dentro del cual se encuentran glándulas de tipo estrógenico en proporción variable que pueden mostrar irregularidad y, ocasionalmente, hiperplasia.

La acción hormonal es fundamental para el desarrollo del endometrio tanto normal como patológico. Alteraciones cuantitativas a nivel de los receptores de estrógeno y progesterona podrían contribuir a la patogenia de los pólipos; siendo ellos el resultado de esta alteración. Su expresión podría corresponder a un aumento localizado de receptores de estrógeno (RE), de una disminución de receptores de progesterona (RP) o de ambos factores. Nuestro objetivo fue evaluar mediante método inmunocitoquímico, la presencia de receptores de estrógeno fraccion alfa y receptores de progesterona, en 9 pacientes portadoras de pólipos endometriales.

La intensidad de la tinción fue evaluada como intensa, moderada, débil o negativa y comparada con muestras control de endometrio normal. Se observó un aumento de RE $\alpha$ en el estroma, en el epitelio glandular y en el endotelio de pequeños vasos que rodean a las glándulas endometriales. Los RP fueron negativos o no cuantificables, en el estroma y en el tejido glandular.

Concluimos que los pólipos endometriales presentan una alteración de la distribución de los receptores con un aumento localizado de los RE $\alpha$ en el estroma y en el epitelio glandular y una disminución de los RP, destacándose la presencia de RE $\alpha$ en las células perivasculares y en el endotelio de pequeños vasos.

PALABRAS CLAVE: Pólipo endometrial; Receptores de estrógeno; Receptores de progesterona.

\section{INTRODUCCIÓN}

Los pólipos endometriales constituyen un hallazgo frecuente en patología endometrial, causando metrorragia y ocasionalmente infertilidad (Wallach, 1972 y Ruiz Velasco et al., 1997). Éstos son masas polipoideas que histológicamente corresponden a endometrio estrogénico con glándulas que pueden mostrar irregularidad epitelial y ocasionalmente hiperplasia, no presentando secreción. En algunas ocasiones, puede verse decidualización en pacientes que estén recibiendo progestágenos (Kurman et al., 1994).

La acción hormonal determina el desarrollo del endometrio tanto normal como patológico (Lessey et al.,1988; Levy et al., 1980; Moutsatsou et al.,1997), las hormonas se unen a sus receptores específicos e inician la respuesta biológica. Los pólipos endometriales se originarían en la capa basal del endometrio y sus receptores serían similares a los de esta capa y sensibles por lo tanto, a la acción de los estrógenos y de la progesterona (Kurman et al.). Se ha postulado que los pólipos podrían ser el resultado de una alteración cuantitativa a nivel de los receptores de estrógeno (RE) y de progesterona (RP) (Maia et al.,1998; Mittal et al.,1996; Taylor et al., 2003).

Se observó la presencia en el útero de receptores de estrógenos en sus dos isoformas alfa y beta (Artega et al.,1998; Taylor et al.; Critchley et al., 2001), llegándose a la conclusión que el principal receptor es el isoforma alfa. 
Nuestro objetivo fue evaluar, mediante método inmunocitoquímico, a los receptores de estrógenos isoforma alfa y a los de progesterona, en 9 pacientes portadoras de pólipos endometriales con la finalidad de identificar posibles modificaciones en ellos que pudieran explicar su patogenia.

\section{MATERIAL Y MÉTODO}

Presentamos 9 pacientes con edades entre los $40 \mathrm{y}$ 55 años, cuyo principal síntoma fue el de metrorragia abundante e intermitente y a las cuales se les diagnosticó pólipo endometrial. En 5 casos, mediante ecografía, se tomó biopsia, la que confirmó el diagnóstico presentando: 1 caso endometrio mixto y 8 casos endometrio estrogénico (dentro de ellos uno con características de pólipo adenomiomatoso).

Las inclusiones se hicieron en paraplast, de las cuales se obtuvieron cortes seriados de 5-7 $\mu \mathrm{m}$. Los análisis morfológicos se hicieron con Hematoxilina y Eosina. (Fig.1 A y B).

Para la inmunocitoquímica las muestras fueron procesadas como describe Sternberger (1979), con el método del PAP, según técnica del segundo anticuerpo. En la serie para los receptores estrogénicos alfa se utilizó como $1^{\text {er }}$ anticuerpo (Ac) o específico, un monoclonal (Dako, M7047), como $2^{\circ} \mathrm{Ac}$ : (-)IgG ratón obtenido en conejo (Dako, Z0109) y el PAP fue PAP-ratón (Dako, P0850).

En la serie para los receptores de progesterona se utilizó como $1^{\text {er }}$ Ac, un policlonal (Dako, A0098), como $2^{\circ} \mathrm{Ac}$ : (-) IgG conejo obtenido en cerdo (Dako, Z0196) y PAP fue PAP-conejo (Dako, Z0113). El revelado se hizo con 3,3'- diaminobenzidina (Dako, S-3000 ó Sigma) y $\mathrm{H}_{2} \mathrm{O}_{2}$ por 1-5 minutos, para luego ser deshidratados y montados en Entellan (Merck).

Los resultados de la ICQ fueron estudiados en un microscopio Zeiss Axiolab con óptica ICS.

Según la intensidad de la tinción se usó la clasificación de: positividad fuerte o marcada $(+++)$, moderada $(++)$, débil o leve (+) y negativa (-). La intensidad de reacción de las muestras fueron comparadas con controles negativos.

Se tomaron macrofotografías con un equipo fotográfico MC80 DX.

\section{RESULTADOS}

Los resultados para RE alfa fueron: 4 de las 9 muestras presentaron positividad de (2+), 3 de las positividad de( $3+)$ y 2 positividad de( 4+.) La reacción positiva fue observada con mayor intensidad en el estroma del pólipo endometrial, siendo negativa en las glándulas. En 3 muestras las células del epitelio superficial evidenciaron reacción positiva en forma de gránulos dispuestos en la zona apical del epitelio cilíndrico secretor (Fig. 2 A y B ). Se observó en 4 muestras, reacción positiva de (4+) para RE en células asociadas a vasos sanguíneos (Fig. 3 A y B ).

Todas las muestras, excepto una, presentaron negatividad para RP. Esta muestra presentó reacción positiva tanto para RE como para RP y pertenecía a una paciente con terapia de reemplazo hormonal.
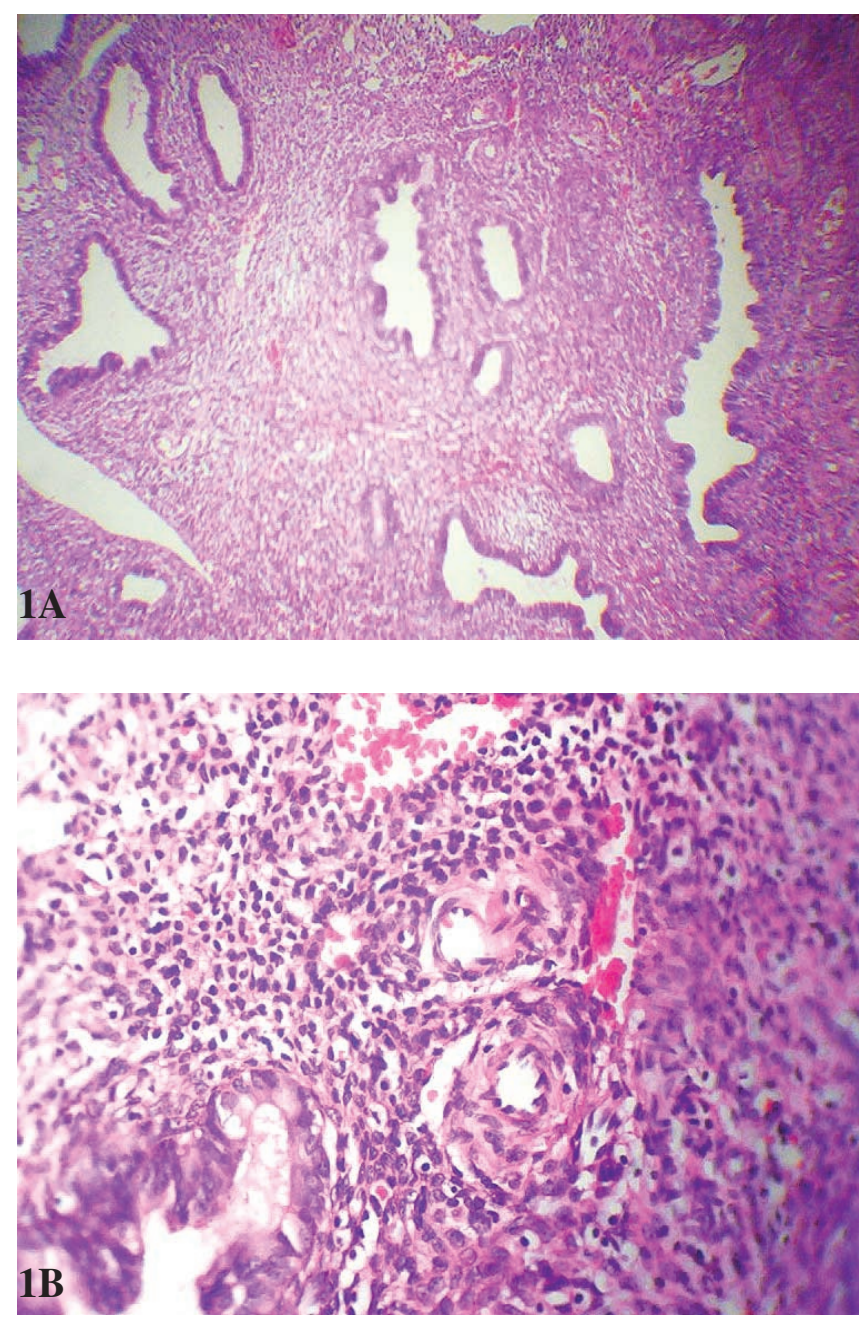

Fig. 1. Pólipo: A. Endometrio de estroma denso con glándulas de tipo estrogénico. 100X. B. Vasos prominentes. $400 \mathrm{X}$. 

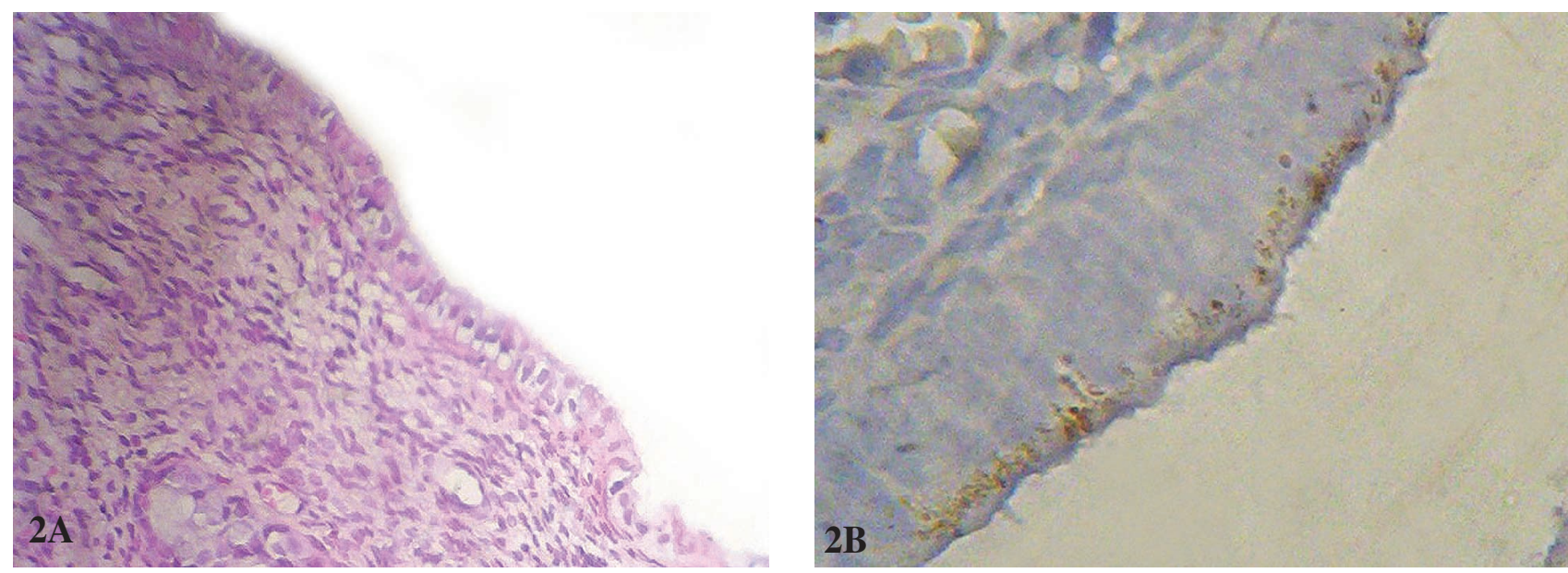

Fig. 2. A. Epitelio y estroma. HE. B y C. Inmunoreacción positiva para

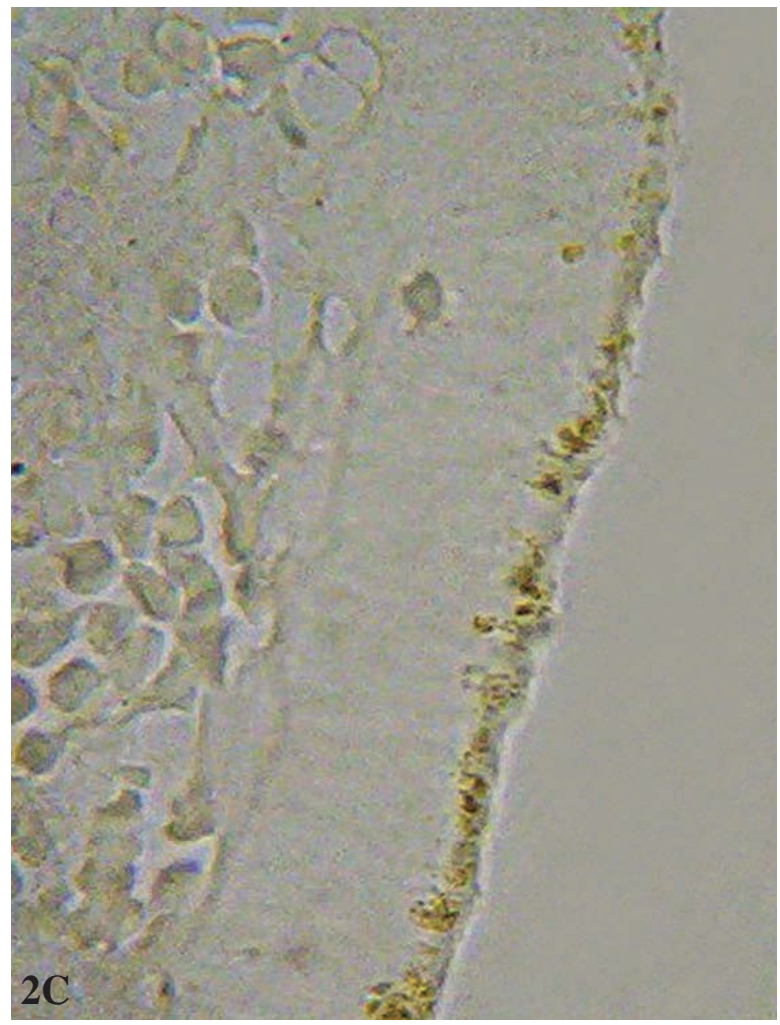

$\mathrm{RE}$ en epitelio en forma de gránulos de secreción.

\section{DISCUSIÓN}

Dentro de las patologías benignas que afectan el endometrio, los pólipos endometriales destacan por ser una de las causas frecuentes de metrorragia y, en algunos casos, pueden ser responsables de infertilidad (Wallach; Ruiz Velasco et $a l$.). Los pólipos endometriales son masas sésiles o pedunculadas que protruyen en la cavidad uterina, su aspecto histológico corresponde a un endometrio proliferativo de estroma fibroso, dentro del cual se encuentran glándulas de tipo estrogénico en proporción variable, que pueden mostrar irregularidad y ocasionalmente hiperplasia. (Kurman et al.). En el 3,1\% evidenciaron hiperplasia con atipia y sólo el $0,8 \%$ resultó ser canceroso, por lo tanto, sólo un 3,9\% constituirían riesgo (Savelli et al., 2003).

Poco se sabe de su patogenia salvo en casos puntuales, donde se relacionó un aumento en la frecuencia de aparición de pólipos endometriales en pacientes que utilizan Tamoxifeno para el tratamiento de cáncer mamario (Silva et al., 1994).
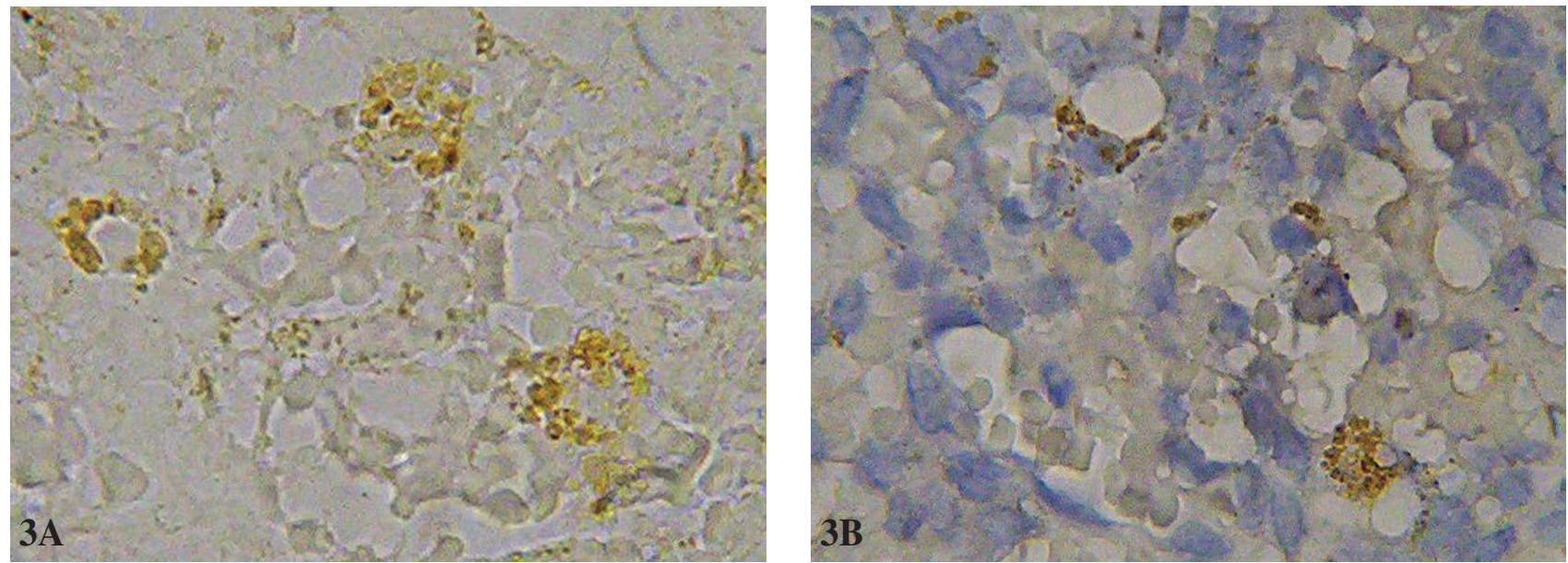

Fig. 3. A y B. Inmunoreacción positiva para RE en el epitelio perivascular y en estroma de pólipo. 400X. 
Las hormonas responsables de los cambios morfológicos del endometrio son los estrógenos y la progesterona, hormonas de tipo esteroidal que se unen a sus receptores específicos y que luego, a través de estimulación genómica directa en sitios promotores, desencadenan la síntesis proteica que producirá los cambios en el tejido endometrial (Arteaga et al.).

El receptor de estrógeno (RE) posee dos isoformas producto de dos genes distintos, estas isoformas son denominadas RE $\alpha$ y RE $\beta$. En el útero se han descrito las dos isoformas, siendo la $\alpha$ el principal receptor proteico que media la clásica acción estrogénica en las glándulas y estroma endometrial.

La progesterona a nivel molecular inhibe la síntesis y reposición de los RE, de tal manera que puede actuar disminuyendo el número de receptores estrogénicos y haciendo que las células disminuyan su reactividad a los mismos.

Una de las hipótesis planteada para explicar la patogenia de los pólipos sería una alteración a nivel de los receptores de estrógeno (RE) y de progesterona (RP), ya sea por un aumento localizado de RE, de una disminución de los RP o la suma de ambos factores (Maia et al.; Mittal et al.; Taylor et al.).

La presencia de los receptores de estrógenos y progesterona en los pólipos respecto del endometrio normal no muestra diferencias significativas en las glándulas, pero si en las células estromales, donde se encontró una marcada reducción de PR y una moderada reducción de RE (Mittal et al.). Esto implicaría que los pólipos no corresponden a endometrio basal, ya que la distribución de receptores en ésta es diferente de la del pólipo, en éste último hay reducción de receptores en las células estromales, mientras que en la capa basal no los hay.

En búsqueda de posibles causas se han realizado estudios genéticos, pensando en cambios citogenéticos en los pólipos endometriales, cambios cromosómicos. que podrían producir aumento de la proliferación (Spelman et al.,1991; Dal Cin et al.,1992; Menasce et al.,1993), sin embargo los resultados no han clarificado su patogenia.

En nuestro estudio observamos que todos los pólipos presentan un marcado aumento de RE $\alpha$ y una casi nula expresión de RP. La expresión de RE fue principalmente de tipo estromal, mientras que a nivel glandular, la expresión se visualizó como gránulos de secreción dentro de las células del epitelio, lo que concuerda parcialmente con los trabajos de Maia et al. y Taylor et al., quienes describieron un aumento de los RE y una débil expresión de RP, tanto en epitelio glandular como en el estroma de los pólipos.

Un hallazgo llamativo en nuestro estudio fue la presencia de RE $\alpha$ en el endotelio, especialmente asociado a los pequeños vasos que circundan el tejido glandular. Critchley et al. describieron la presencia de $\operatorname{RE} \alpha$ y $\operatorname{RE} \beta$ en las células perivasculares y sólo RE $\beta$ en el endotelio de los vasos del endometrio humano normal y sugieren que estos últimos mediarían alguno de los efectos directos de los estrógenos sobre los vasos, teniendo un efecto inhibitorio sobre la angiogénesis. En nuestro estudio realizado en endometrio patológico, como es el pólipo, la presencia aumentada de REo estaría sustentando una proliferación vascular aumentada con carencia de efectos inhibitorios sobre ella.

Concluimos que los pólipos endometriales presentan una alteración de la distribución de los receptores, con un aumento localizado de los RE $\alpha$ en el estroma y en el epitelio glandular y una expresión casi nula de RP, destacándose la presencia de RE $\alpha$ en células perivasculares y en el endotelio de pequeños vasos. El aumento de los RE variaría la expresión de los RP, que disminuirían y dejarían de actuar como controladores naturales. La presencia aumentada de RE $\alpha$ en el endotelio de pequeños vasos es un hallazgo interesante que debería considerarse en investigaciones futuras.

VASCONCELlOS, A.; VILlaGRÁN, E.; ASTUDILlO, M. \& CABEZAS, P. Immunocytochemistry study of strogen receiver alfa fraction and progesterone in endometrial polyps. Int. J. Morphol., 23(2):123-127, 2005.

SUMMARY: The endometrial polyps are a frequent cause of anormal bleeding and in same cases responsible of sterility. Their pathogenesis is poorly understand. They are masses sessiles or pedunculated that protrudes into the endometrial cavity. The histologic pattern resembles proliferative endometrium with fibrous stroma and estrogenic glands that can show irregularity and occasionally hyperplasia.

The hormonal action is fundamental for the development of normal and pathologic endometrium. Quantitative alterations of the estrogen and progesterone receptors contributes to the pathogenesis of endometrial polyps. They could arise from localized overexpression of estrogen receptors (ER), reduced expression of progesterone receptors (PR) or both. This study was undertaken to evaluate with inmunocytochemistry the presence of estrogen receptors alfa and progesterone receptors in endometrial polyps of 9 patients.

The intensity of staining was record on a scale high, moderate and weak or negative and compared with the staining in normal endometrium. High levels of ER $\alpha$ was seen in glandular epithelium, stroma and endothelial cells of capillaries that are surrounding the glands. The PR are negatives or very weak in stoma and glands.

We conclude that endometrial polyps have a alterate distribution of the receptors with and increase number of stromal and glandular epitheliuml ER alfa and a decrease of PR detaching the large number of ER $\alpha$ in perivascular cells and in endotelial cells.

KEYWORDS: Endometrial polyps; Estrogen receptors; Progesterone receptors. 


\section{REFERENCIAS BIBLIOGRÁFICAS}

Arteaga, U. E. Nuevos conceptos en el mecanismo de acción celular de los estrógenos. Boletín de la Sociedad Chilena de Climaterio, 3(4):3-4, 1998.

Critchley, H. O. D.; Brenner, R. M.; Henderson, T. A.; Williams, K.; Nayak, N. R.; Slayden O. D.; Millar, M. R. \& Saunders, P. T. K. Estrogen Receptor B, But Not Estrogen Receptor, Is Present in the Vascular Endothelium of the Human and Nonhuman Primate Endometrium. J. Clinical Endocrinology \& Metabolism., $86(3): 1370-8,2001$.

Dal Cin, P. De Wolf, F.; Klerckx, P. \& van der Berg, H. The 6 p21 chromosome region is non randomly involved in endometrial polyps. Gynecol. Oncol., 46:393-6, 1992.

Kurman, R. \& Mazur, M. Benign diseases of the endometrium. In:Kurman RJ. ed Blaustein A: Phathology of the Female Genital Tract 4 th ed. New York, SpringerVerlag., 1994. pp. 394-7.

Lessey, B. A.; Killam, A. P.; Metzger, D.; Haney, A. F. et al. Immunohistochemical analysis of human uterine estrogen and progesterone receptors throughout the menstrual cycle. J. Clin. Endocrinol. metab., 67:334-40, 1988.

Levy, C.; Robel, P.; Gautray, J. P.; De Brux, J.; Verma U.; Descomps, B.; Bauliee, E. \& Exchenng, B. Estradiol and progesterone receptors in human endometrium: normal and anormal menstrual cycles and early pregnancy. Am. J. Obstet. Gynecol., 136:646-51, 1980.

Maia, H.; Maltez, A.; Calmon, L. C.; Oliveira, M.; Marques, D. \& Coutinho, E. M. Histopathology and steroid receptors in in endometrial polyps of postmenopausal patients under hormone replacement therapy. Gynaecol. Endosc., 7:267-72, 1998.

Menasce, L. P.; Whitw, G. R.; Harrison, C. J. \& Boyle, J.M. Localization of the estrogen receptor locus (ESR) to chromosome $6 \mathrm{q} 25.1$ by FISH and simple post-FISH banding technique. Genomics, 17:263-5, 1993.

Mittal, K.; Scwartz, L.; Goswami, S. \& Demopoulus, R. Estrogen and progesterone receptor expression in endometrial polyps. J. Gynecol. Pathol., 15 (4):345-8, 1996.

Moutsatsou, P. \& Serekis, C. E. Estrogen and progesterone receptors in the endometrium Ann. N. Y. Acad. Sci., 30: 816: 99-115, 1997.
Ruiz Velasco, V.; González Alfani, G.; Pliego Sánchez, L. \& Alamillo Vera, M. Endometrial pathology and infertility. Fertil. Steril., 67:687-92, 1997.

Savelli, L.; De Iaco, P.; Santini, D.; Rosati, F.; Ghi, T.; Pignotti, E. \& Bovicelli, L. Histopathologic features and risk factors for benignity, hyperplasia, and cancer in endometrial polyps. Am. J. Obstet. Gynecol., 188 (4): 927-31, 2003.

Silva, E. G.; Tornos, C. S. \& Follen-Mitchell, M. Malignant neoplasms of the uterine corpus in patients treated for breast carcinoma: the effects of tamoxifen. Int. J. Gynecol. Pathol. 13:248-58, 1994.

Spelman, F.; Cin, P. D.; Van Roy, N. et al. Is t (6:20) (p21:q13) a characteristic chromosome change in endometrial polyps? Genes Chromosom Cancer, 3:3189, 1991.

Sternberger, L. A. The unlabled antibody (PAP) method introduction. J. Histochem. Cytochem., 27(12):1657-65, 1979.

Taylor, L. J.; Jackson, T. L.; Reid, J. G. \& Duffy, S. R. G. The differential expression of estrogen receptors, progesterone receptors, Bcl-2 and Ki67 in endometrial polyps. Int. J. Obstetrics and Gynaecology., 110(9):7948, 2003.

Wallach, E. The uterine factor in infertility. Fertil. Steril., 23:138-48, 1972.

Dirección para correspondencia:

Prof. Dra. Adriana Vasconcellos Costa

Facultad de Medicina

Universidad de La Frontera

Casilla $54-\mathcal{D}$

Temuco - CHILE

Email:avascon@ufro.cl

Recibido : 14-04-2005

Aceptado: 22-03-2005 
